B. M. Kim • S. Y. Kim • S. Lee • Y. J. Shin • B. H. Min • M. Bendayan · I. S. Park

\title{
Clusterin induces differentiation of pancreatic duct cells into insulin-secreting cells
}

Received: 30 June 2005 / Accepted: 20 October 2005 / Published online: 13 January 2006

(C) Springer-Verlag 2006

\begin{abstract}
Aims/hypothesis: We recently reported that expression of the gene encoding clusterin $(\mathrm{Clu})$ is upregulated in the regenerating pancreas, particularly in tissues undergoing differentiation. This led us to propose that clusterin participates in the cytodifferentiation of pancreatic tissue, particularly the endocrine islet cells. The aim of this study was to investigate whether clusterin induces the differentiation of duct-lining cells into insulin-secreting cells. Methods: We isolated ductal tissue from rat pancreas and cultured it to develop epithelial cell explants for transfection of the $C l u$ cDNA as well as for treatment of clusterin protein. Results: The number of newly differentiated insulin cells increased 6.9-fold upon $\mathrm{Clu}$ overexpression compared with controls. Ins $1 \mathrm{mRNA}$ and peptide levels were also increased. Furthermore, glucose-stimulated insulin secretion was observed in the differentiated insulin cells. These cells were immunoreactive for insulin and C-peptide, but negative for other islet hormones and for cytokeratin-20, which indicates a fully differentiated state. Insulin cell differentiation was also increased in a dose-dependent manner by treating duct cells in culture with clusterin, indicating a growth-factor-like action of clusterin in insulin cell differentiation. Conclusions/ interpretation: These results suggest that clusterin can be considered as a potential morphogenic factor that promotes differentiation of pancreatic beta cells.
\end{abstract}

B. M. Kim · S. Y. Kim · S. Lee · I. S. Park $(\bowtie)$

Department of Anatomy, College of Medicine, Inha University, Incheon, 401-103, Choong-Gu,

Shinheung-Dong, Incheon 400-103, Korea

e-mail: sunpark@inha.ac.kr

Tel.: +82-32-8900911

Fax: +82-32-8842105

Y. J. Shin · B. H. Min

Department of Pharmacology and BK21

Program for Medical Sciences,

College of Medicine, Korea University,

Seoul, South Korea

M. Bendayan

Department of Pathology and Cell Biology,

Faculty of Medicine, University of Montreal,

QC, Canada
Keywords Beta cells · Clusterin - Differentiation ·

Duct cells

Abbreviations FITC: fluorescein isothiocyanate

PCNA: proliferating cell nuclear antigen .

TRITC: tetramethylrhodamine isothiocyanate

\section{Introduction}

Pancreatic tissue is composed of endocrine and exocrine cells that are derived from common progenitor cells during embryogenesis [1,2]. Pancreatic development is instigated by epithelial invagination of the foregut, giving rise to a multitubular duct tree containing the progenitor cells [3]. It is well established that the dynamic growth of pancreatic tissue from these stem cells is interrupted after the perinatal stage, and that pancreatic growth in adult life is predominantly maintained by the proliferation of pre-existing cells. This may account for the poor reconstitution of islet cells after their loss or functional impairment in diabetes. Beta cell regeneration has thus become a cell therapy strategy for the treatment of diabetes.

It has been reported that duct cells and/or stem cells from the duct lining isolated from the adult pancreas can differentiate into islet endocrine cells upon stimulation with foetal mesenchyme, which is known to be rich in various growth and/or transcription factors [4]. We have also shown that the pancreatic tissue, including insulinsecreting cells, can be regenerated in the adult pancreas by neogenic motivation $[5,6]$. Taken together, these studies suggest that some morphogenic factors presenting in the process of tissue regeneration can be used for development of beta cells from the duct cells.

Clusterin is a disulphide-linked heterodimeric protein that is secreted by a broad range of cells, and has been assigned several functions. There is growing evidence that clusterin is involved in tissue remodelling in response to hormonal regulation and injury [7-10]. In particular, a role as a differentiation factor has been suggested [11-13], and we reported that clusterin is indeed involved in pancreatic 
islet formation during embryonic development, as well as in islet regeneration $[6,14-16]$. We have recently observed the transient expression of clusterin in regenerating tissue after pancreatectomy along with the process of neogenesis. Furthermore, ectopic expression of clusterin by pancreatic duct cells stimulated the proliferation of these cells [6]. Based on these results, we propose that clusterin can reactivate stem cells from the duct lining, leading to their differentiation into insulin-secreting cells.

In this study, we examined the effect of clusterin on the differentiation of pancreatic duct and/or stem cells in the duct lining into hormone-secreting cells by overexpressing the gene encoding clusterin $(\mathrm{Clu})$ and by clusterin treatment.

\section{Materials and methods}

Isolation and culture of pancreatic duct fragments

Pancreatic ducts were isolated from male Sprague-Dawley rats (120-130 g body weight; Daehan Experimental Animals, Seoul, Korea) by modification of a method for isolation of pancreatic islets [6, 17]. In brief, the whole pancreas was removed from the rats after laparotomy, and injected with $5 \mathrm{ml}$ collagenase $\mathrm{P}(1.5 \mathrm{mg} / \mathrm{ml}$; Roche, Mannheim, Germany) in RPMI 1640 medium (Life Technologies, Grand Island, NY, USA). The tissue fragments were then chopped and digested with the same medium for $30 \mathrm{~min}$ at $37^{\circ} \mathrm{C}$. The digests were washed with Hanks' balanced salt solution and transferred to culture medium for rapid sedimentation. After suspension, small fragments of duct tissues, 100-150 $\mu \mathrm{m}$ in diameter, were selected under a stereomicroscope and plated onto cover slips for basic culture. The tissues were cultured with RPMI medium containing $10 \%$ FBS and antibiotics for 3 days, and subjected to conditional culture with $\mathrm{Clu}$ overexpression or clusterin treatment for an additional 3 days.

\section{Overproduction of clusterin by $\mathrm{Clu}$ cDNA transfection}

Clu cDNA from nucleotide +63 to nucleotide +1406 (GenBank accession number M64723) was obtained from rat brain total RNA and cloned into the expression vector pcDNA3 (Invitrogen, Groningen, the Netherlands). After basic culture, the cells were transferred to DMEM for transfection experiments using Effectene Reagent (Qiagen, Valencia, CA, USA). In brief, pcDNA3-rCLU $(0.4 \mu \mathrm{g})$ was mixed with the enhancer in $100 \mu \mathrm{l}$ DNA condensation buffer, and Effectene $(10 \mu \mathrm{l})$ was added to induce the formation of the transfection complex. Duct cells were incubated with culture medium containing the EffecteneDNA complex for $6 \mathrm{~h}$, after which time the medium was changed to the medium lacking the transfection reagent. For the control, the vector plasmid (pcDNA3) was transfected in the same manner. Cells with or without $\mathrm{Clu}$ overexpression were cultured for an additional 3 days, and washed with PBS for further experiments. To estimate the transfection efficiency, the pGFP vector (Clontech, Palo Alto, CA, USA) was cotransfected into the duct cells along with pcDNA3-rCLU, and the percentage of green fluorescent protein-producing cells assessed $24 \mathrm{~h}$ after transfection was $53.35 \pm 3.06 \%$ (Fig. 1d). Overexpression of Clu was confirmed in the cell explants by immunocytochemistry and in the culture medium by western blot analysis.

Culture in clusterin-free medium

After overexpression of $\mathrm{Clu}$, the culture medium was collected for 3 days, the culture medium was immunoprecipitated with rabbit anti-clusterin antibody $(2 \mu \mathrm{g} / \mathrm{ml}$; Santa Cruz Biotechnology, Santa Cruz, CA, USA) and $15 \mu \mathrm{l}$ protein A/G (Oncogene, Darmstadt, Germany) for removal of the secreted clusterin, and the clusterin-free supernatant fraction was collected after centrifugation. This clusterinfree medium was applied to the duct cell culture. After 3 days of culture with the conditioned medium, insulin cell differentiation was compared with that of cultures incubated with clusterin-rich medium. Removal of clusterin protein from the medium was confirmed by western blot analysis.

Culture in the presence of exogenous clusterin

To examine the effect of exogenous clusterin on insulin cell differentiation, we isolated clusterin from human serum by means of polyethylene glycol (PEG) precipitation (12-23\%) and a clusterin monoclonal antibody (1G8)-affinity column chromatography. Briefly, human plasma was precipitated with 12\% PEG ( $\mathrm{M}_{\mathrm{r}}$ 3350; Sigma, St Louis, MO, USA) overnight. After centrifugation, the supernatant fraction was reprecipitated with $23 \% \mathrm{PEG}$, and the precipitate was applied to a diethylaminoethyl (DEAE) column and heparin affinity column, as described previously $[18,19]$. Clusterinpositive fractions were dialysed with binding buffer (potassium phosphate buffer, $10 \mathrm{mmol} / \mathrm{l}, \mathrm{pH}$ 7.4) and applied to a clusterin monoclonal affinity chromatography. The monoclonal antibody was generated using human full-length clusterin expressed in E. coli as an antigen. Clusterin fractions were eluted with the same binding buffer containing guanidine- $\mathrm{HCl}(2 \mathrm{~mol} / \mathrm{l})$ and $\mathrm{NaCl}(0.5 \mathrm{~mol} / \mathrm{l})$ and dialysed with the same buffer as above and lyophilised. Purified clusterin $(1-100 \mathrm{ng} / \mathrm{ml})$ was added to the cells after basic culture. The culture medium was substituted with fresh medium every day during the conditional culture.

Determination of beta cell differentiation by immunocytochemistry

To examine cellular differentiation, the cells were subjected to immunocytochemistry. Immunostaining was carried out with the avidin-biotin-peroxidase complex technique or by indirect immunofluorescence. The samples were incubated with the primary antibodies for $24 \mathrm{~h}$ at $4^{\circ} \mathrm{C}$. The primary antibodies used were mouse anti-insulin (Bio- 
Genex, San Ramon, CA, USA), goat anti-rat C-peptide (Linco Research, St Charles, MO, USA), rabbit antiglucagon (Dako, Carpinteria, CA, USA) and mouse anticytokeratin 20 antibodies (Dako) to detect islet or duct cells. Mouse anti-proliferating cell nuclear antigen (PCNA) antibody (Zymed Laboratories, San Francisco, CA, USA) and goat anti-clusterin antibody (Santa Cruz Biotechnology, Santa Cruz, CA, USA) were also used. After incubation with the primary antibodies the cells were incubated with the corresponding secondary antibodies, including biotinylated goat anti-mouse IgG, goat anti-rabbit IgG and rabbit anti-goat $\mathrm{IgG}$, and then treated with the avidin-biotin-peroxidase complex (ABC, Vector Laboratories, Burlingame, CA, USA). The cytochemical reaction was visualised with diaminobenzidine hydrochloride (Sigma). To generate immunofluorescence, fluorescein isothiocyanate (FITC)- or tetramethylrhodamine isothiocyanate (TRITC)-conjugated anti-mouse or antirabbit IgG (Jackson ImmunoResearch, West Grove, PA, USA) was used as the secondary antibody.

\section{Double immunocytochemistry}

After insulin immunostaining, the samples were subjected to double immunolabelling for clusterin, glucagon, cytokeratin-20 and PCNA. Double immunofluorescent stainings were carried out with FITC-conjugated anti-mouse IgG (1:200; Vector Laboratories) and TRITC-conjugated anti-rabbit $\operatorname{IgG}(1: 400$; Jackson ImmunoResearch) as the secondary antibodies. Double staining for insulin and cytokeratin-20 was performed with an immunoperoxidase staining procedure.

\section{In situ hybridisation}

The cells fixed with $4 \%$ paraformaldehyde were subjected to in situ hybridisation as described previously [14]. The cultured cells were hybridized with the solution containing digoxigenin-tagged oligonucleotide for insulin $(2 \mu \mathrm{g} / \mathrm{ml}$; R\&D Systems, Minneapolis, MN, USA) and incubated with alkaline phosphatase conjugated anti-digoxigenin antibody (Boehringer Mannheim, Mannheim, Germany). Hybridisation signal was revealed by nitroblue-tetrazolium and 5-bromo-4-chloro-3-indolyl phosphate toluidinium.

\section{Western blot analysis}

An aliquot of each experimental medium was mixed with an equal volume of sample buffer (125 mmol Tris $/ 1,4 \%$ SDS, $10 \%$ glycerol, $0.006 \%$ bromophenol blue, $2 \% \beta$ mercaptoethanol) and boiled for $5 \mathrm{~min}$. After protein denaturation, the samples were subjected to $10 \%$ SDSPAGE and transferred to a nitrocellulose membrane in buffer (39 mmol glycine/l, $48 \mathrm{mmol}$ Tris base/1, $0.037 \%$
SDS, 20\% methanol). The membrane was pre-incubated with $1 \%$ blocking solution, and then incubated with goat anti-clusterin antibody for $24 \mathrm{~h}$ at $4^{\circ} \mathrm{C}$. Detection was carried out with chemiluminescence substrate.

Northern blot analysis

Total cellular RNA was isolated from cell samples according to previously described protocols [20]. Total RNA $(10 \mu \mathrm{g})$ was separated on an agarose (1\%) gel containing $2.2 \mathrm{~mol} / 1$ formaldehyde and transferred to a nylon membrane. The blot was baked at $120^{\circ} \mathrm{C}$ for $30 \mathrm{~min}$ and prehybridised in hybridisation buffer at $60^{\circ} \mathrm{C}$ for $1 \mathrm{~h}$. Hybridisation was performed with digoxigenin-labelled rat insulin cRNA. After hybridisation with the probe at $60^{\circ} \mathrm{C}$ for $16 \mathrm{~h}$, the membrane was washed twice in $0.1 \times$ standard saline citrate $-0.1 \%$ SDS at $65^{\circ} \mathrm{C}$ for $15 \mathrm{~min}$ each and revealed with CSPD (Roche) after 30 min exposure to X-ray film.

Measurement of insulin secretion

pcDNA3-rCLU- or pcDNA3-transfected cells were cultured in six-well plates for 3 days and the media were collected and diluted 1:10 for measurement of insulin. Immunoasssay of insulin was performed using an ultrasensitive insulin ELISA kit showing standard range 0.02$5.5 \mathrm{ng} / \mathrm{ml}$ (Alpco Diagnostics, Windham, NH, USA) according to the manufacturer's instructions.

Modulation of insulin secretion by glucose stimulation was monitored by treating the cells with various concentrations of glucose. After Clu cDNA transfection and 3 days of conditional culture, the cells were washed with PBS and then incubated with Krebs-Ringer bicarbonate buffer containing $\mathrm{CaCl}_{2}(2.4 \mathrm{mmol} / \mathrm{l}), \mathrm{NaCl}(120 \mathrm{mmol} / \mathrm{l})$,

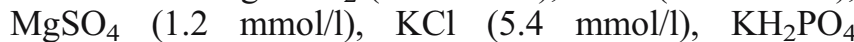
$(1.2 \mathrm{mmol} / \mathrm{l})$ and HEPES $(20 \mathrm{mmol} / \mathrm{l})$. The cells were exposed to a series of media containing various concentrations of glucose $(0,5,10,15$ or $20 \mathrm{mmol} / \mathrm{l})$ for $20 \mathrm{~min}$ and each buffer solution was collected for determination of insulin content by immunoassay. Glucose-dependent insulin secretion was also determined by the combination of immunoprecipitation and western blot analysis [21].

\section{Morphometry}

For morphometric analysis, we counted the insulin- and glucagon-positive cells as well as non-immunoreactive duct epithelial cells of the explants in the immunocytochemically stained cover-slip $(22 \times 22 \mathrm{~mm})$, which displayed about 40-50 explants. To estimate the growth rate of the cell explants, the areas of the explants were measured on the day of transfection using phase-contrast microphotography. The explants with a similar size (200$300 \mu \mathrm{m}$ in diameter) were chosen for morphometric 
analysis. The same explants were photographed 3 days after transfection to assess the increment in their area. Explant expansion was calculated by deducting the initial area from the final one. Data on differentiation are presented as the numbers of insulin- or glucagon-positive cells per thousand cells in the explants.

\section{Statistical analysis}

Results were analysed statistically with ANOVA and Student's $t$ test. We deemed $p$ values less than 0.05 to 0.001 to be significant. All results are expressed as mean values \pm SEM and data were analysed using SAS software (version 6.12; SAS Institute, Cary, NC, USA).
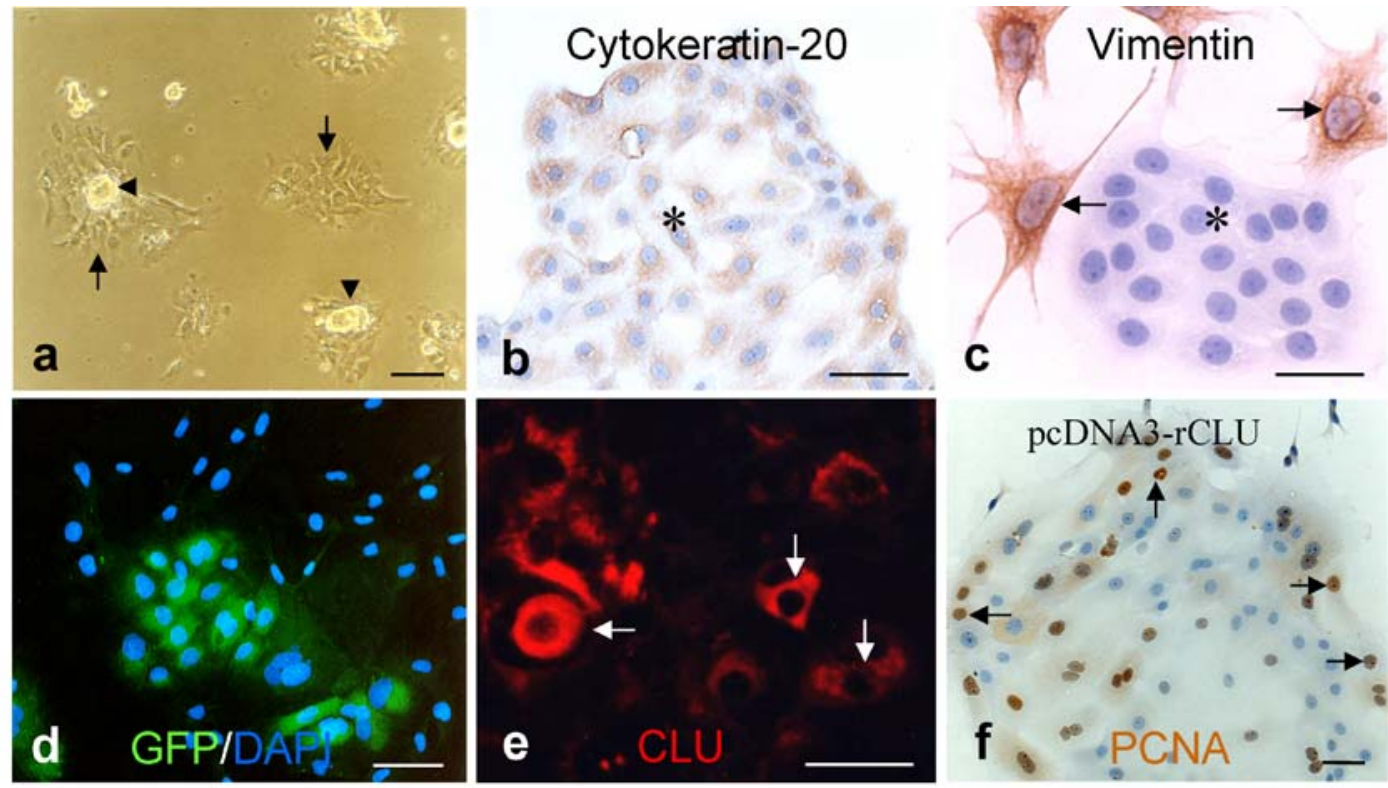

g

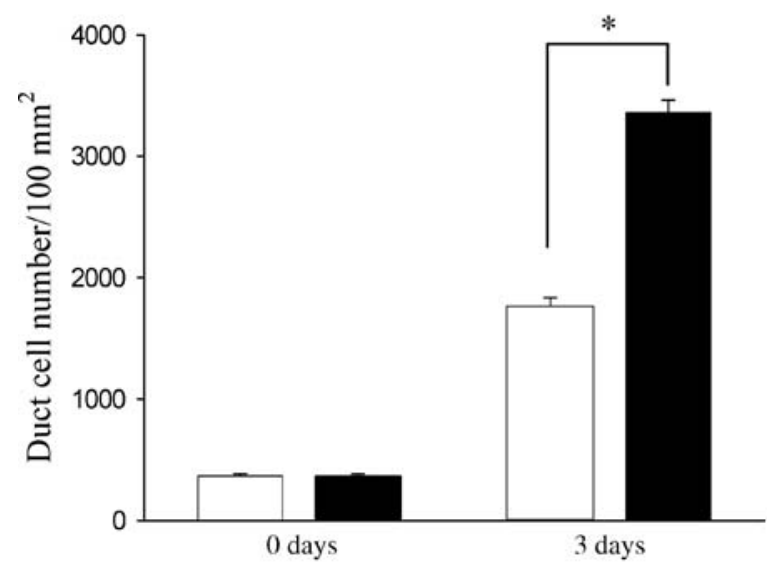

Fig. 1 Characteristics and growth of the isolated duct cells. The duct fragments (arrowheads in a) formed epithelial explants (arrows in a) on days 1-2 of the basic culture. The duct cells of explant mostly expressed cytokeratin-20 (asterisk in b), but not vimentin (asterisk in c). The fibroblast-like cells were found separately from explants and expressed vimentin (arrows in c). These morphological and immunocytochemical characteristics were retained over the experimental period. A GFP vector and $C l u$ cDNA (pGFP/pcDNA3rCLU in b) were co-transfected for estimation of transfection efficiency (d). Ectopic expression of clusterin in the cells of the explants (arrows in e) was confirmed by immunofluorescence staining from the culture of $\mathrm{Clu}$ overexpression. During conditional culture, extensive growth of the explants with cytoproliferation was illustrated in an explant displaying many cells with PCNA-positive h

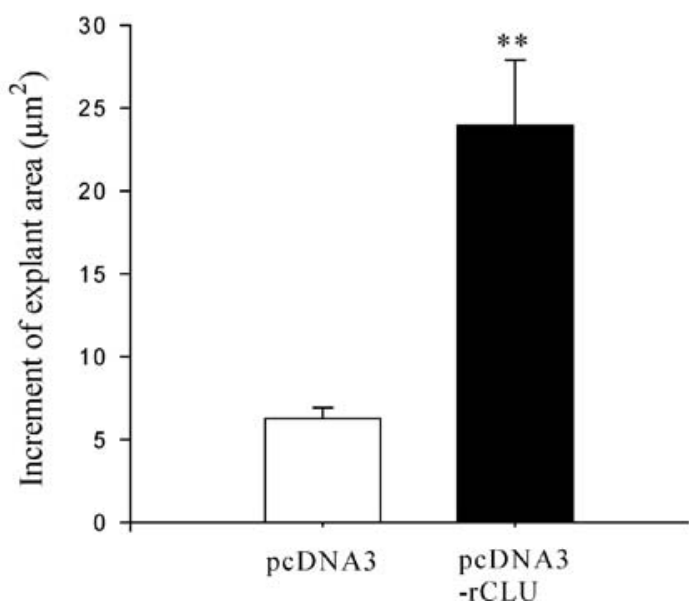

nuclei at the periphery (arrows in f). After 3 days of conditional culture, insulin-secreting cells were hardly detected in the mocktransfected control (d), whereas clusters of insulin-secreting cells were seen in the explants after $\mathrm{Clu}$ overexpression (e). The number of duct epithelial cells increased more rapidly in the cultures overexpressing Clu (solid bars in g) compared with the mocktransfected controls (empty bars in $\mathbf{g}$ ). The increments in explant areas were greater in cultures transfected with $C l u$ cDNA (solid bars in $\mathbf{h}$ ) than in the control cultures (empty bars in $\mathbf{h}$ ). The growth rate of the explants was also estimated by measuring the area of expansion during conditional culture $(\mathbf{h})$. The area of the explants was measured on the day of transfection and on the last day of conditional culture. Bar represents $25 \mu \mathrm{m}$. ${ }^{*} p<0.05, * * p<0.001$ by Student's $t$ test compared with the control 


\section{Results}

Morphology of isolated pancreatic duct cells

The tissue fragments of the isolated ducts adhered to the cover slips and the epithelial cells expended to form monolayer explants during the days 1-2 of basic culture (Fig. 1a). The cells of the explants were closely associated along their cell membranes and most of them were immunoreactive for cytokeratin-20, reflecting the epithelial profile of duct cells (Fig. 1b). On the other hand, cells with long cytoplasmic processes were present on days 2-3 and grew separately from the explants. These fibroblast-like cells were not immunoreactive for cytokeratin-20, but positive for vimentin (Fig. 1c). They appeared to be by stromal cells at the time of duct isolation. After transfection experiments, we found faster-growing cell explants under conditions of $\mathrm{Clu}$ overexpression, whereas the explants without $C l u$ cDNA transfection grew slowly as the culture progressed (Fig. 1d,g,h). PCNA, a nuclear signal of cytoproliferation, was strongly expressed in these cells, particularly at the peripheries of the explants (Fig. 1f). The initial number of the duct epithelial cells at time of transfection experiments was $394.8 \pm 17.1$ cells $/ 100 \mathrm{~mm}^{2}$ of the cover slip. The number of cells increased more rapidly in the cultures overexpressing $C l u$ compared with the mock-transfected controls $(1,763.5 \pm 71.2$ vs $3,358.7 \pm 103.6$ cells $/ 100 \mathrm{~mm}^{2}$ of the cover slip) (Fig. 1g). The increments in explant areas were 3.8-fold greater in cultures transfected with $\mathrm{Clu}$ cDNA than in the control cultures without $\mathrm{Clu}$ overexpression $\left(23.98 \pm 3.92\right.$ vs $\left.6.28 \pm 0.64 \mu \mathrm{m}^{2}, p<0.001\right)$ (Fig. 1h).
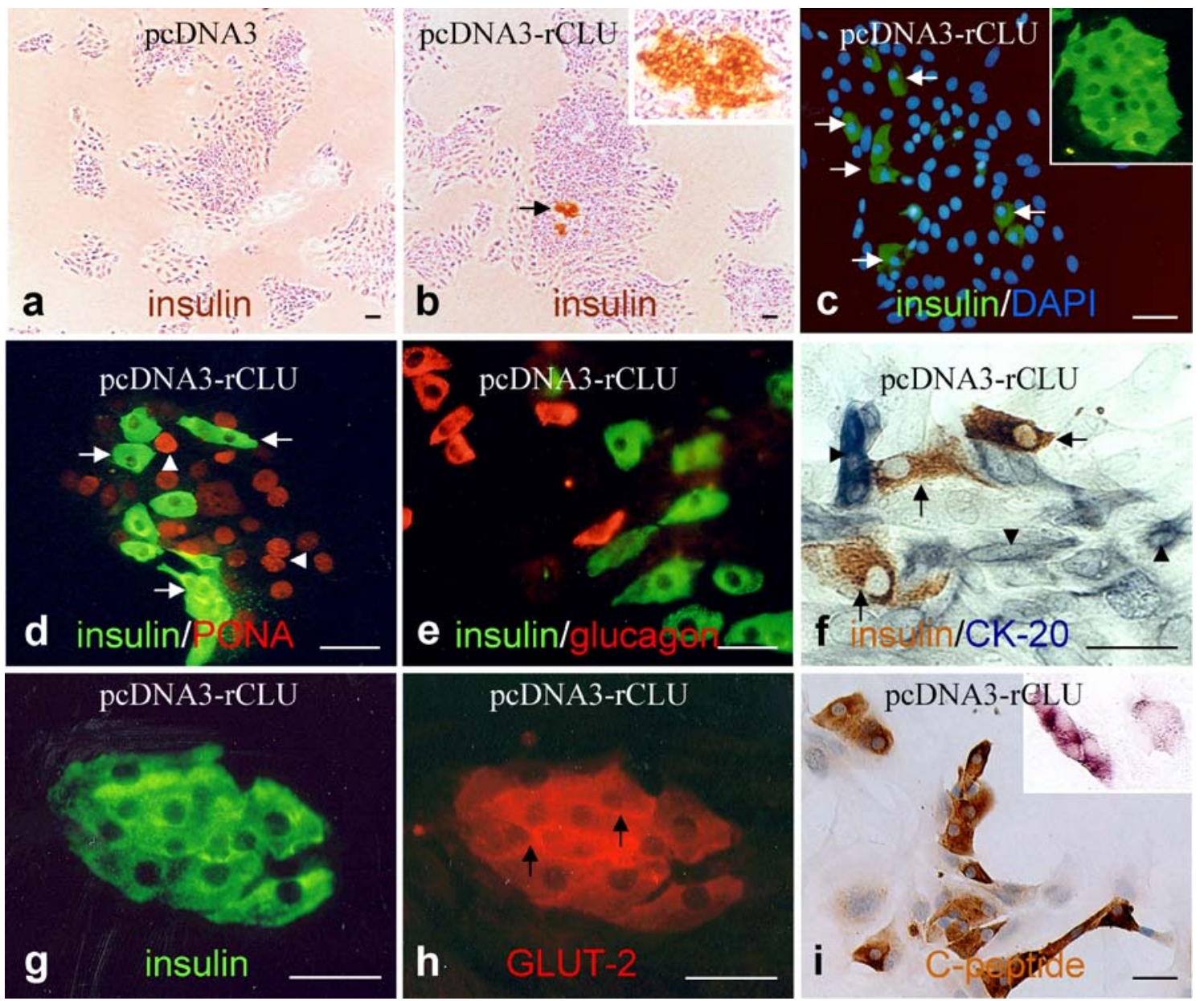

Fig. 2 Morphological profiles of the insulin-secreting cell development. Although few insulin-positive cells were detected in the mock-transfected (pcDNA3) control after 3 days of conditional culture (a), clusters of insulin-secreting cells were seen in the explants after $\mathrm{Clu}$ overexpression (b). The inset of $\mathbf{b}$ shows a higher magnification of the insulin cell cluster, which is indicated by an arrow. The insulin-positive cells were populated as single cells (arrows in c) or formed an islet-like cell cluster (inset in c). The insulin-containing cells (arrows in $\mathbf{d}$, labelled with green FITC) were devoid of proliferation signal in their nuclei, whereas the insulin-

negative cells demonstrated a distinctive red TRITC fluorescence for PCNA immunoreactivity (arrowheads in d). No overlapping of insulin (green in e and brown in f) with glucagon (red in e), or cytokeratin 20-positive cells (blue-black in $\mathbf{f}$ ) was detected by double immunofluorescence (b) or immunoperoxidase labelling (f). In contrast, most of the insulin cells (g) showed GLUT-2 immunolabelling (h), particularly at the cell membrane (arrows in h). Production of C-peptide (i) and Ins 1 mRNA expression (inset of $\mathbf{b}$ ) were also detected in the insulin-producing cells by immunocytochemistry and in situ hybridisation, respectively. Bar represents $25 \mu \mathrm{m}$ 
Transfection of Clu cDNA and expression of ectoptic clusterin

Overexpression of $\mathrm{Clu}$ was confirmed by western blot analysis and immunocytochemistry (Fig. 1d,e, Fig. 4a). Clusterin immunoreactivity was detected in a subpopulation of the explant cells after $\mathrm{Clu}$ cDNA transfection (Fig. 2e), whereas no clusterin immunoreactivity was detected in the cells of the mock-transfected control. Because clusterin is a secretory molecule, we investigated the presence of the protein in the medium using western blot analysis. We confirmed the presence of a $42-\mathrm{kDa}$ protein in the pcDNA3-rCLU-transfected cell media that was barely detectable in the medium of the mocktransfected controls (Fig. 4a).

\section{Effect of Clu overexpression on cell differentiation}

To examine the differentiation of islet cells, immunocytochemistry was performed to reveal insulin and glucagon in the transfected cells. Only small numbers of insulinproducing cells were detected in some explants before transfection experiments (Figs. 2a, 3a). After overexpression of Clu, the population of insulin-producing cells increased 6.9-fold compared with the pcDNA3-transfected controls $(6.62 \pm 0.5732$ vs $0.95 \pm 0.1792$ cells $/ 1,000$ cells, $p<0.05$; Figs. 2b, 3a). The insulin-producing cells were, however, unevenly distributed among the explants. They tended to appear as single cells or as clusters only in some explants, while being absent in many explants (Fig. 2b-g). Therefore, the cell density appeared to be higher than the morphometric values in the explants containing insulinpositive cells (Fig. 3a). Some of the insulin cells were recognisable by their relatively smaller nuclei and reduced
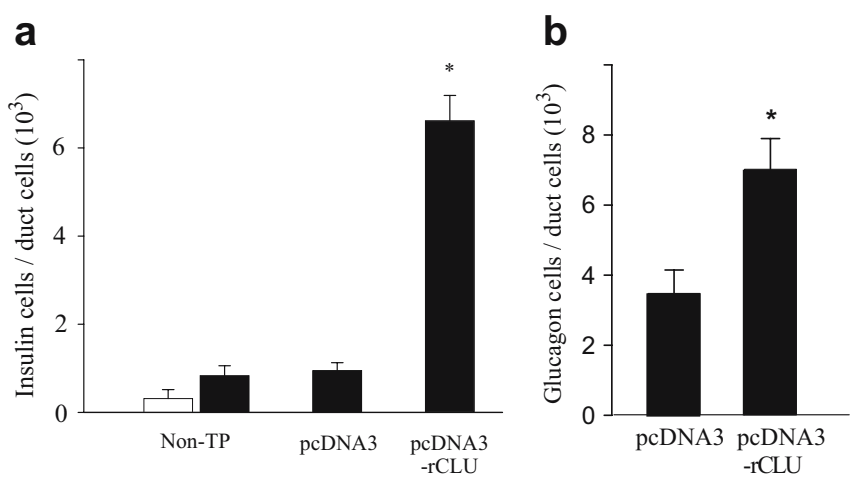

Fig. 3 Evaluation of the endocrine cell differentiation by quantifying the number of insulin and glucagon cells after $C l u$ overexpression. Beta cell differentiation was significantly increased by $\mathrm{Clu}$ overexpression (pcDNA3-rCLU in a) compared with the mock-transfected control (pcDNA3 in a), or cultured without transfection procedures (non-TP in a) during the conditional culture. An increase in glucagonpositive cells was also observed in the duct cell culture by $\mathrm{Clu}$ overexpression, as shown in $\mathbf{b}$. The data are shown as mean values \pm SEM. Data were analysed using Student's $t$ test ( $n=15$ in each group). Empty bar, beta cell number on the final day of basic culture; solid bar, number of insulin or glucagon cells after the conditional cultures. ${ }^{*} p<0.05$ vs the controls of non-TP and pcDNA3

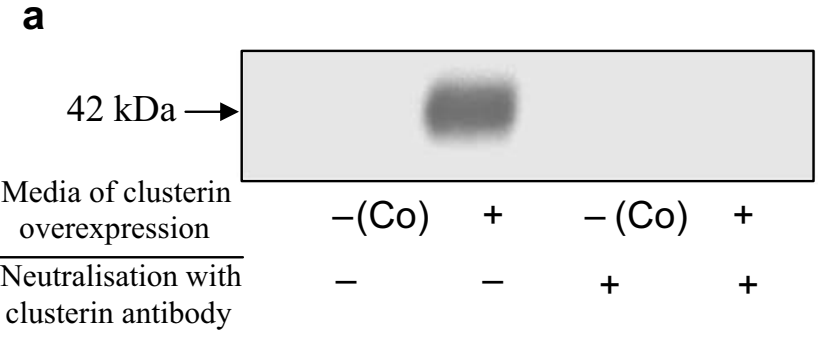

\section{b}

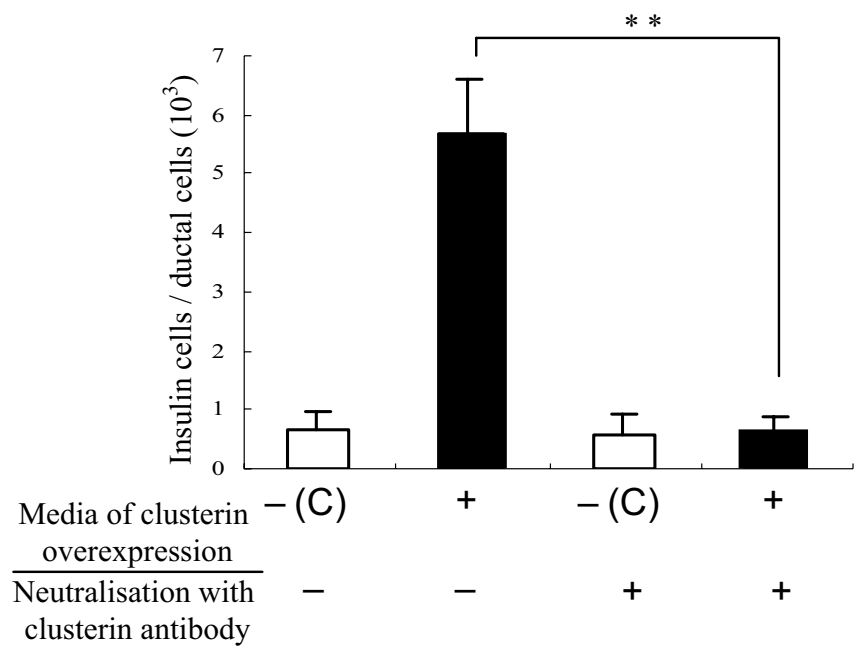

C
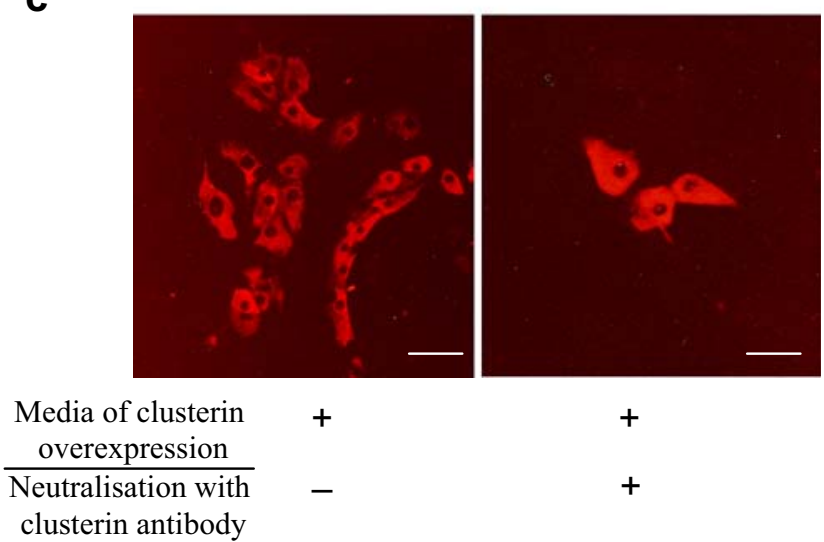

Fig. 4 Modification of beta cell differentiation in clusterin-depleted medium. To examine the extracellular action of clusterin, cells were cultured with clusterin-depleted medium collected from the culture of $C l u$ overexpression. The secreted clusterin in the culture medium was removed by treatment with anti-clusterin antibody. Depletion of the protein was confirmed by western blot analysis as shown in (a) (last lane), whereas clusterin was identified in the conditioned medium collected from cultures of $\mathrm{Clu}$ cDNA-transfected cells (second lane in a). The control medium (c) collected from the conditional culture of mock-transfected control did not contain clusterin, as shown in the first and third lanes in (a). Increased insulin cell differentiation was observed in the culture using conditioned medium containing clusterin, whereas no stimulatory effect was observed when the medium was depleted of clusterin $(\mathbf{b}, \mathbf{c})$. Data are shown as mean values \pm SEM ( $n=13$ in each group). $* * p<0.001$ by Student's $t$ test compared with the controls. Bar in c represents $20 \mu \mathrm{m}$ 
cytoplasm. No insulin immunoreactivity was detected in the fibroblast-like cells. No overlapping immunoreactivity for insulin, glucagon or cytokeratin-20 was detected in these cells (Fig. 2f,g). In contrast, the insulin-producing cells showed GLUT-2 immunoreactivity on their cell membrane (Fig. 2g,h). We also found cells producing Cpeptide and expressing Ins 1 mRNA in the explants after $\mathrm{Clu}$ overexpression (Fig. 2i). These data indicate that the insulin-producing cells could synthesise insulin and react with the glucose stimulation for insulin secretion. Glucagon-positive cells were also increased during the process of cell culture by $\mathrm{Clu}$ overexpression (Fig. 3b).

Modification of insulin cell differentiation

in clusterin-depleted medium

Stimulation of insulin cell differentiation by $\mathrm{Clu}$ cDNA transfection may be caused by the intracellular or extracellular action of clusterin. The extracellular action of clusterin is more likely, because it is a secretory protein. To assess the extracellular action of clusterin, the explants were incubated in conditioned medium collected from cultures with or without $C l u$ cDNA transfection. The same media were used for cultures after the removal of clusterin by immunoprecipitation with a specific antibody. Clusterin depletion was confirmed by western blot analysis (Fig. 4a). Insulin cell differentiation was not increased in cultures in clusterin-free medium (Fig. 4b,c). This implies that clusterin molecules secreted from the transfected cells do induce insulin cell differentiation via extracellular signalling.

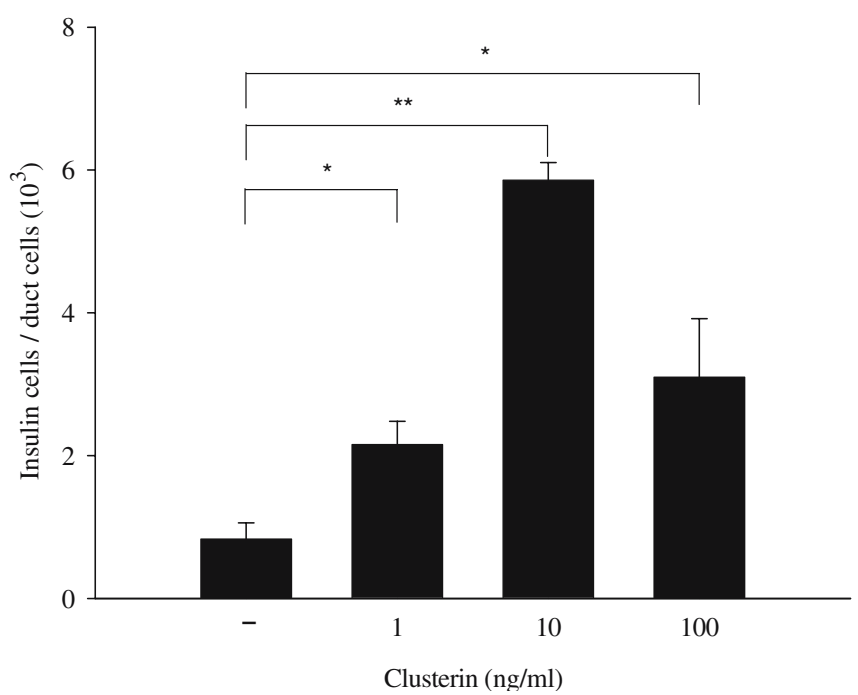

Fig. 5 Determination of exogenous clusterin action on insulin cell differentiation. Clusterin purified from human serum was added to conditional cultures. Insulin cell differentiation increased dose dependently up to $10 \mathrm{ng} / \mathrm{ml}$. Higher concentrations of clusterin $(>10 \mathrm{ng} / \mathrm{ml})$ did not accelerate cell differentiation. Data are shown as mean values $\pm \operatorname{SEM}$ ( $n=5$ in each group). ${ }^{*} p<0.05$ and $* * p<0.001$ by Student's $t$ test vs control (-)
Effect of exogenous clusterin on insulin cell differentiation

The extracellular action of clusterin was confirmed by direct treatment of the cell explants with clusterin. Significant increases in insulin cell differentiation were seen in cultures exposed to clusterin, particularly at $10 \mathrm{ng} / \mathrm{ml}$ (Fig. 5). This further supports the notion that exogenous clusterin acts on the cells and triggers their differentiation into insulin cells, reflecting a paracrine action of clusterin in the process of pancreatic neogenesis. Interestingly, higher doses of clusterin $(>10 \mathrm{ng} / \mathrm{ml})$ did not accelerate the process of insulin cell differentiation.
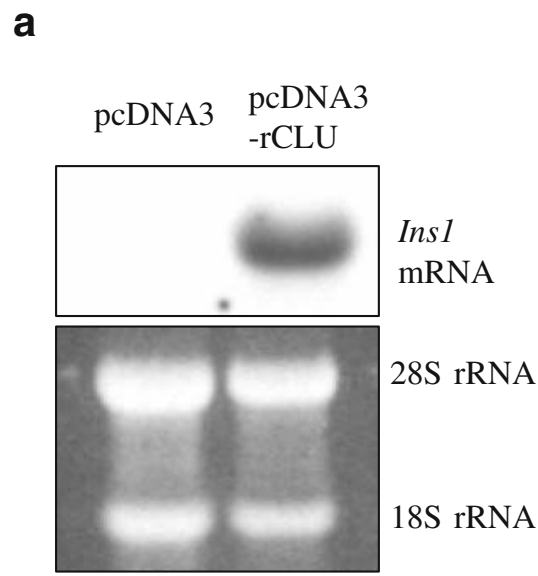

b

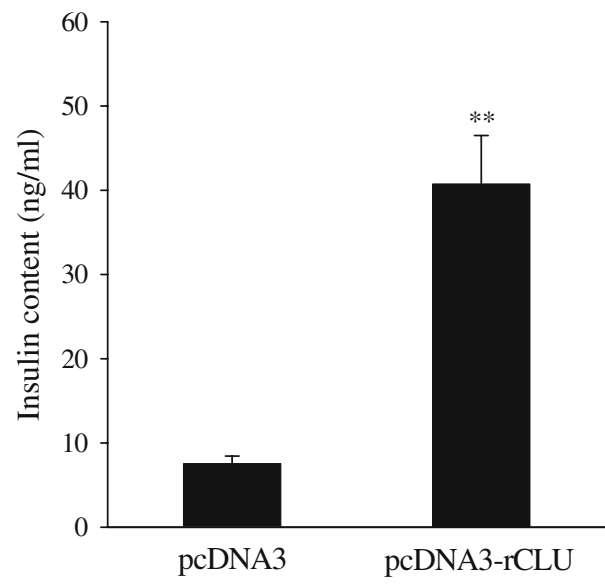

Fig. 6 Ins 1 mRNA expression and detection of secreted insulin in culture media. Ins 1 mRNA expression was determined by northern blot analysis. Total cellular RNA was isolated from pcDNA3-or pcDNA3-rCLU-transfected duct cells and subjected to northern blot analysis (a). Insulin released into the medium was measured by immunoassay (b). The pcDNA3-rCLU- and pcDNA3-transfected duct cells were cultured in six-well plates for 3 days, and insulin accumulation in the culture medium was then normalised against total cellular protein content for each individual culture $(n=18$ in each group). Both northern blot analysis and immunoassay showed a significant increase in Ins 1 mRNA expression and insulin secretion from the culture of $\mathrm{Clu}$ overexpression. ${ }^{* *} p<0.05$ vs control 


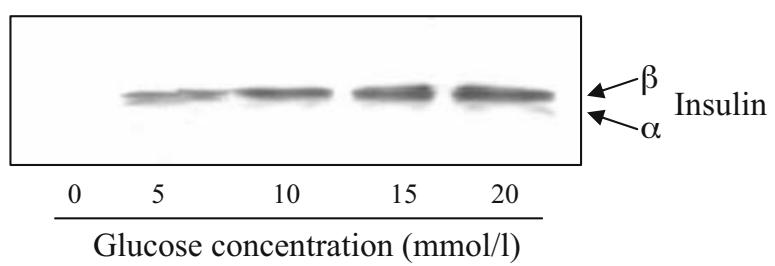

b

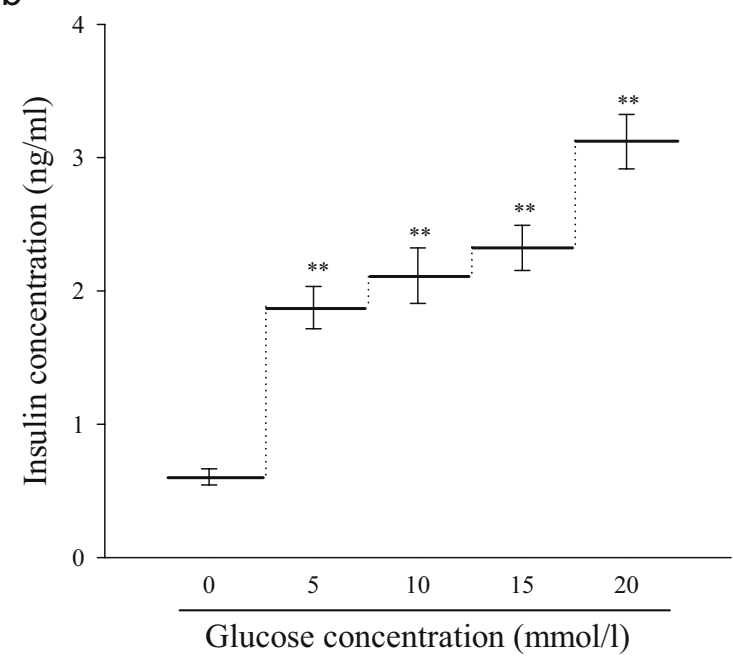

Fig. 7 Glucose-dependent insulin secretion from cultures with $\mathrm{Clu}$ overexpression. A combination of immunoprecipitation, western blot analysis and immunoassay for insulin showed a dose-dependent increase in insulin content induced by glucose concentrations $(0,5$, $10,15$ and $20 \mathrm{mmol} / \mathrm{l})$ in the culture medium after Clu overexpression $(\mathbf{a}, \mathbf{b})$. The blot represents the data from five independent experiments. ${ }^{* *} p<0.001$ vs $0 \mathrm{mmol} / 1$

Identification of insulin secretion by cells in culture on $\mathrm{Clu}$ overexpression

Northern blot analysis showed a marked expression of Ins 1 mRNA in cell cultures after transfection with pcDNA3rCLU, whereas cells transfected with pcDNA3 were devoid of Ins $1 \mathrm{mRNA}$ (Fig. 6a). Insulin release assessed by immunoassay (Fig. 6b) was considerably higher in the media from cultures overexpressing $\mathrm{Clu}$ than in those from the controls $(7.55 \pm 0.89$ vs $40.73 \pm 5.76 \mathrm{ng} / \mathrm{ml}, p<0.001)$. Using western blotting analysis and immunoassay, we determined modification of insulin secretion by the increase of glucose stimulation after $\mathrm{Clu}$ overexpression (Fig. 7). A dosedependent increment of insulin in response to glucose concentrations in the medium implies that differentiation of the functional beta cells under clusterin-rich conditions.

\section{Discussion}

Clusterin is an intriguing protein that plays diverse biological roles in various organs. We have demonstrated specific action of clusterin in the reconstruction and remodelling of the endocrine pancreas $[6,14-16]$. Clusterin is transiently produced by foetal endocrine pancreatic cells and clusterin might be involved in the development of the pancreas [16]. This transient production of clusterin at specific time points of pancreas development and cell differentiation during pancreas regeneration implies that clusterin is a regulatory factor for cytodifferentiation, as well as for replication. In this study, we demonstrate that clusterin strongly stimulates duct cell differentiation into insulin-secreting cells under in vitro culture conditions. Overexpression of $\mathrm{Clu}$ induced an increase in beta cell differentiation. Clusterin thus appears to be a potent regulator of beta cell morphogenesis. Clusterin is a highly glycosylated heterodimeric protein. This protein is modified in the endoplasmic reticulum and is proteolytically cleaved in the Golgi apparatus to generate discrete alpha and beta chains prior to its secretion [22]. Secreted clusterin has been established as a major form of the protein that exerts diverse tissue effects [23, 24]. For instance, clusterin is known to act in cell protection through the actions of extracellular molecular chaperones; this activity is similar to, but more potent than that of small heat shock proteins [2529]. Recently, Miwa et al. [30] showed that this cytoprotective mechanism of clusterin might be associated with the differentiation of vascular smooth muscle cells. Although it is more likely that clusterin exerts its cell differentiation action extracellularly, the exact mechanism remains to be elucidated. In the extracellular milieu, clusterin participates in specific interactions with a diverse array of native biological molecules including LRP-2 (lipoprotein receptor-related protein 2, also known as gp330 or megalin), which is involved in ligand endocytosis at the surfaces of certain epithelia $[31,32]$. This implies receptor-mediated activities of clusterin through megalin or other yet to be identified receptors. The extracellular or paracrine action of clusterin was confirmed by the modulation of insulin cell differentiation by exogenous clusterin. Although exogenous clusterin was less potent than Clu overexpression, it did accelerate insulin cell differentiation. Moreover, no clusterin-induced beta cell differentiation was observed when cells were cultured in clusterin-depleted medium. These data indicate that clusterin is a potent extracellular regulator of beta cell differentiation.

Recently, Sipione et al. [33] reported that beta cells that differentiated in vitro from embryonic stem cells could not be true insulin cells, because they were devoid of typical insulin granules and rarely showed immunoreactivity for Cpeptide. These authors assumed that the observed insulin immunoreactivity was due to insulin uptake from the medium rather than to endogenously synthesised insulin. In our study, however, beta cells did differentiate from duct or stem cells and were clearly immunoreactive for insulin and Cpeptide. Furthermore, the presence of Ins 1 mRNA was revealed in their cytoplasm, both by in situ hybridisation and northern blot analysis. Although we did not use insulincontaining culture media, significant amounts of insulin were detected in the culture media. We also confirmed glucose-dependent insulin secretion by the newly differentiated beta cells. These data indicate that the insulin cells that developed during culture were well differentiated and fully responsive to glucose. We assume that these beta cells are derived from cells present in the isolated duct explants, 
since no insulin-expressing cells were seen in these explants during the first 3 days of basic culture. After this initial period of 3 days, differentiation was actively triggered by clusterin. This finding strongly supports the existence of epithelial stem cells or precursor cells in the explants that are triggered by clusterin to differentiate. Our results are consistent with the existence of precursor cells that remain within the adult pancreatic ducts and retain the potential to be transformed into endocrine cells upon appropriate external stimuli $[2,34-36]$.

Acknowledgements This work was supported by the Korea Science and Engineering Foundation (R01-2002-000-00263-0) and the Biodiscovery Programme from the Ministry of the Science and Technology. B. M. Kim and S. Y. Kim contributed equally to this study.

\section{References}

1. Hui H, Wright C, Perfetti R (2001) Glucagon-like peptide 1 induces differentiation of islet duodenal homeobox-1-positive pancreatic ductal cells into insulin-secreting cells. Diabetes 50: 785-796

2. Teitelman G, Lee JK (1987) Cell lineage analysis of pancreatic islet development: glucagon and insulin cells arise from catecholaminergic precursors present in the pancreatic duct. Dev Biol 121:454-466

3. Dudek RW, Freinkel N, Lewis NJ, Hellerstrom C, Johnson RC (1980) Morphologic study of cultured pancreatic fetal islets during maturation of the insulin stimulus-secretion mechanism. Diabetes 29:15-21

4. Dudek RW, Lawrence IE Jr, Hill RS, Johnson RC (1991) Induction of islet cytodifferentiation by fetal mesenchyme in adult pancreatic ductal epithelium. Diabetes 40:1041-1048

5. Kim SY, Lee SH, Kim BM et al (2004) Activation of nestinpositive duct stem (NPDS) cells in pancreas upon neogenic motivation and possible cytodifferentiation into insulin-secreting cells from NPDS cells. Dev Dyn 230:1-11

6. Min BH, Kim BM, Lee SH, Kang SW, Bendayan M, Park IS (2003) Clusterin expression in the early process of pancreas regeneration in the pancreatectomized rat. J Histochem Cytochem 51:1355-1365

7. Sensibar JA, Sutkowski DM, Raffo A et al (1995) Prevention of cell death induced by tumor necrosis factor alpha in LNCaP cells by overexpression of sulfated glycoprotein-2 (clusterin). Cancer Res 55:2431-2437

8. Connor J, Buttyan R, Olsson CA, D'Agati V, O'Toole K, Sawczuk IS (1991) SGP-2 expression as a genetic marker of progressive cellular pathology in experimental hydronephrosis. Kidney Int 39:1098-1103

9. Bandyk MG, Sawczuk IS, Olsson CA, Katz AE, Buttyan R (1990) Characterization of the products of a gene expressed during androgen-programmed cell death and their potential use as a marker of urogenital injury. J Urol 143:407-413

10. May PC, Lampert-Etchells M, Johnson SA, Poirier J, Masters JN, Finch CE (1990) Dynamics of gene expression for a hippocampal glycoprotein elevated in Alzheimer's disease and in response to experimental lesions in rat. Neuron 5:831-839

11. Suh E, Wang Z, Swain GP, Tenniswood M, Traber PG (2001) Clusterin gene transcription is activated by caudal-related homeobox genes in intestinal epithelium. Am J Physiol Gastrointest Liver Physiol 280:G149-G156
12. Schedin P, Mitrenga T, Kaeck M (2000) Estrous cycle regulation of mammary epithelial cell proliferation, differentiation, and death in the Sprague-Dawley rat: a model for investigating the role of estrous cycling in mammary carcinogenesis. J Mammary Gland Biol Neoplasia 5:211-225

13. French LE, Chonn A, Ducrest D et al (1993) Murine clusterin: molecular cloning and mRNA localization of a gene associated with epithelial differentiation processes during embryogenesis. J Cell Biol 122:1119-1123

14. Kim BM, Han YM, Shin YJ, Min BH, Park IS (2001) Clusterin expression during regeneration of the pancreatic islet cells in the streptozotocin-induced diabetic rats. Diabetologia 44:2192-2202

15. Park IS, Che YZ, Bendayan M, Kang SW, Min BH (1999) Upregulation of clusterin (sulfated glycoprotein-2) in pancreatic islet cells upon streptozotocin injection to rats. J Endocrinol 162:57-65

16. Min BH, Jeong SY, Kang SW et al (1998) Transient expression of clusterin (sulfated glycoprotein-2) during development of rat pancreas. J Endocrinol 158:43-52

17. Bouwens L, Braet F, Heimberg H (1995) Identification of rat pancreatic duct cells by their expression of cytokeratins 7, 19, and 20 in vivo and after isolation and culture. J Histochem Cytochem 43:245-253

18. Choi NH, Nakano Y, Tobe T, Mazda T, Tomita M (1990) Incorporation of SP-40,40 into the soluble membrane attack complex (SMAC, SC5b-9) of complement. Int Immunol 2:413-417

19. Pankhurst GJ, Bennett CA, Easterbrook-Smith SB (1998) Characterization of the heparin-binding properties of human clusterin. Biochemistry 37:4823-4830

20. Chomczynski P, Sacchi N (1987) Single-step method of RNA isolation by acid guanidinium thiocyanate-phenol-chloroform extraction. Anal Biochem 162:156-159

21. Bradford MM (1976) A rapid and sensitive method for the quantitation of microgram quantities of protein utilizing the principle of protein-dye binding. Anal Biochem 72:248-254

22. O'Sullivan J, Whyte L, Drake J, Tenniswood M (2003) Alterations in the post-translational modification and intracellular trafficking of clusterin in MCF-7 cells during apoptosis. Cell Death Differ 10:914-927

23. Sintich SM, Steinberg J, Kozlowski JM et al (1999) Cytotoxic sensitivity to tumor necrosis factor-alpha in PC3 and LNCaP prostatic cancer cells is regulated by extracellular levels of SGP-2 (clusterin). Prostate 39:87-93

24. Aronow BJ, Lund SD, Brown TL, Harmony JA, Witte DP (1993) Apolipoprotein J expression at fluid-tissue interfaces: potential role in barrier cytoprotection. Proc Natl Acad Sci USA 90:725-729

25. Lakins JN, Poon S, Easterbrook-Smith SB, Carver JA, Tenniswood MP, Wilson MR (2002) Evidence that clusterin has discrete chaperone and ligand binding sites. Biochemistry 41:282-291

26. Rosenberg ME, Girton R, Finkel D et al (2002) Apolipoprotein $\mathrm{J} /$ clusterin prevents a progressive glomerulopathy of aging. Mol Cell Biol 22:1893-1902

27. Cervellera M, Raschella G, Santilli G et al (2000) Direct transactivation of the anti-apoptotic gene apolipoprotein $\mathrm{J}$ (clusterin) by B-MYB. J Biol Chem 275:21055-21060

28. Kang SW, Lim SW, Choi SH et al (2000) Antisense oligonucleotide of clusterin mRNA induces apoptotic cell death and prevents adhesion of rat ASC-17D Sertoli cells. Mol Cells 10:193-198

29. Humphreys DT, Carver JA, Easterbrook-Smith SB, Wilson MR (1999) Clusterin has chaperone-like activity similar to that of small heat shock proteins. J Biol Chem 274:6875-6881

30. Miwa Y, Takahashi-Yanaga F, Morimoto S, Sasaguri T (2004) Involvement of clusterin in 15-deoxy-delta12,14-prostaglandin J2-induced vascular smooth muscle cell differentiation. Biochem Biophys Res Commun 319:163-168 
31. Strickland DK, Kounnas MZ, Argraves WS (1995) LDL receptor-related protein: a multiligand receptor for lipoprotein and proteinase catabolism. FASEB J 9:890-898

32. Krieger M, Herz J (1994) Structures and functions of multiligand lipoprotein receptors: macrophage scavenger receptors and LDL receptor-related protein (LRP). Annu Rev Biochem 63:601-637

33. Sipione S, Eshpeter A, Lyon JG, Korbutt GS, Bleackley RC (2004) Insulin expressing cells from differentiated embryonic stem cells are not beta cells. Diabetologia 47:499-508
34. Zulewski H, Abraham EJ, Gerlach MJ et al (2001) Multipotential nestin-positive stem cells isolated from adult pancreatic islets differentiate ex vivo into pancreatic endocrine, exocrine, and hepatic phenotypes. Diabetes 50:521-533

35. Cornelius JG, Tchernev V, Kao KJ, Peck AB (1997) In vitrogeneration of islets in long-term cultures of pluripotent stem cells from adult mouse pancreas. Horm Metab Res 29:271-277

36. Herrera PL, Huarte J, Sanvito F, Meda P, Orci L, Vassalli JD (1991) Embryogenesis of the murine endocrine pancreas; early expression of pancreatic polypeptide gene. Development $113: 1257-1265$ 